\title{
Vitamin D deficiency and insufficiency in Africa and the Middlle East, despite year-round sunny days
}

R J Green, ${ }^{1}$ PhD, DSc; G Samy, ${ }^{2}$ MD, PhD; M S Miqdady, ${ }^{3,4}$ MD; M El-Hodhod, ${ }^{5}$ MD; O O Akinyinka, ${ }^{6}$ MB BS, PhD; G Saleh, ${ }^{7}$ MD; J Haddad, ${ }^{8} \mathrm{MD}$; S A Alsaedi, ${ }^{9} \mathrm{MD}$; A Y Mersal, ${ }^{10} \mathrm{MB}$ BS, FRCPC; A Edris, ${ }^{11} \mathrm{MD} ;$ M Salah, ${ }^{12} \mathrm{MD}$

${ }^{1}$ Department of Paediatrics and Child Health, Faculty of Health Sciences, University of Pretoria, South Africa

${ }^{2}$ Department of Child Health and Nutrition, Institute of Postgraduate Childhood Studies, Ain Shams University, Cairo, Egypt

${ }^{3}$ Division of Hepatology and Nutrition, Department of Pediatric Gastroenterology, Sheikh Khalifa Medical City, United Arab Emirates

${ }^{4}$ Adjunct Staff, Cleveland Clinic, USA

${ }^{5}$ Department of Pediatric Gastroenterology and Endoscopy, Faculty of Medicine, Ain Shams University, Cairo, Egypt

${ }^{6}$ Department of Paediatrics, College of Medicine, University of Ibadan, Ibadan, Nigeria

${ }^{7}$ National Nutrition Institute, Cairo, Egypt

${ }^{8}$ Department of Pediatrics, Faculty of Medicine, Balamand University, Beirut, Lebanon

${ }^{9}$ Department of Pediatrics in ICU Section, King Abdulaziz University, Jeddah, Saudi Arabia

${ }^{10}$ Department of Pediatrics, King Faisal Specialist Hospital and RC, Jeddah, Saudi Arabia

${ }^{11}$ Department of Pediatrics and Neonatology, Faculty of Medicine, Cairo University, Cairo, Egypt

${ }^{12}$ Medical Affairs and R\&D Department, Wyeth Nutrition, Nestlé (Middle East), United Arab Emirates

Corresponding author: RJ Green (robin.green@up.ac.za) 
Exposure to sunlight, specifically ultraviolet B (UVB), is essential for cutaneous vitamin D synthesis. Despite significant daily sunlight availability in Africa and the Middle East, persons living in these regions are frequently vitamin D insufficient or deficient. Vitamin D insufficiency (25-hydroxyvitamin $\mathrm{D}(25(\mathrm{OH}) \mathrm{D})$ between $15 \mathrm{and} 20 \mathrm{ng} / \mathrm{mL}$ ( 37.5 - $50 \mathrm{nmol} / \mathrm{L})$ ) has been described in various population groups, ranging from $5 \%$ to $80 \%$. Risk factors include traditional dress and avoidance of sunlight exposure, and multiple dietary factors as a result of specific cultural beliefs. Vitamin D resistance due to calcium deficiency mechanisms has been described in similar population groups, which may lead to hypovitaminosis D.

Should the new diseases related to hypovitaminosis D prove to be truly associated, Africa and the Middle East will become an epicentre for many of these conditions. Urgent attention will need to be paid to cultural dress and dietary behaviours if hypovitaminosis D is to be taken seriously. Should such factors not be correctable, new strategies for supplementation or food fortification will have to be devised.

S Afr Med J 2015;105(7):603-605. DOI:10.7196/SAMJnew.7785

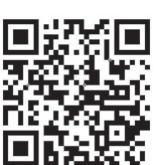

The subject of vitamin D insufficiency has become topical since an increase in the number of reports in the medical literature of health-related problems in children and adults with vitamin D insufficiency. It is important to assess vitamin D status before frank deficiency, because many conditions are linked to this condition. Vitamin D insufficiency and deficiency are extremely common in Africa and the Middle East, despite these regions having high levels of sunlight exposure in summer and winter. This important paradox may have many explanations, which need to be defined for corrective action to be taken for children and adults at risk of hypovitaminosis D.

\section{Vitamin D metabolism}

Exposure to sunlight, specifically ultraviolet B (UVB), is essential for cutaneous vitamin D synthesis; UVB radiation is higher at midday than at other times of the day. During spring, summer and autumn, 10 - 15 minutes of sun exposure between $10 \mathrm{~h} 00$ and $15 \mathrm{~h} 00$ are sufficient for adequate vitamin $\mathrm{D}$ synthesis in light-skinned individuals. ${ }^{[1]}$ However, most Asian Indians require three times as much sun exposure as lightskinned individuals to achieve equivalent vitamin D concentrations, and individuals with very dark skin pigmentation (e.g. some with African ancestry) require 6 - 10 times as much exposure as lightskinned individuals. ${ }^{[2,3]}$ The use of sunscreens and sunblock with a sun protection factor of 30 may decrease vitamin D synthetic capacity by as much as $95 \% .{ }^{[4]}$ Staying indoors for long periods can also cause reduced vitamin D synthesis, ${ }^{[5]}$ which may lead to low vitamin D levels in disabled children and those who stay primarily indoors. ${ }^{[6]}$

Less than $10 \%$ of vitamin $\mathrm{D}$ is derived from dietary sources in the absence of food fortification or use of supplements. Both the $D_{2}$ and $D_{3}$ forms are used for food fortification. The primary natural (unfortified) dietary sources of vitamin D are oily fish (salmon, mackerel, sardines), cod liver oil, liver and organ meats, and egg yolk. Children typically consume few of these sources consistently.

Because of the scarcity of natural dietary sources, vitamin D is fortified in many foods, particularly milk and milk products, orange juice, bread and cereals. Infant formulas in the USA are required to contain 40 - $100 \mathrm{IU}$ vitamin D/100 kcal (usually providing at least $400 \mathrm{IU} / \mathrm{L}$ ), and milk and orange juice that are labelled vitamin $\mathrm{D}$ fortified are required to contain at least $400 \mathrm{IU} / \mathrm{L}$.

The third trimester in pregnancy is a critical time for vitamin $\mathrm{D}$ transfer, because this is when the fetal skeleton becomes calcified, requiring increased activation of 25-hydroxyvitamin $\mathrm{D}(25(\mathrm{OH}) \mathrm{D})$ to $1,25(\mathrm{OH}) 2 \mathrm{D}$ in the maternal kidneys and placenta. Vitamin D levels are particularly low in premature infants, who have less time to accumulate vitamin $\mathrm{D}$ from the mother through placental transfer. ${ }^{[7]}$

The vitamin D content of breastmilk is low (15 - $50 \mathrm{IU} / \mathrm{L})$, even in a mother with sufficient vitamin $\mathrm{D}$, and exclusively breastfed infants consuming an average of $750 \mathrm{~mL}$ of breastmilk daily ingest only 10 - 40 IU vitamin D in the absence of sun exposure or supplement use. Vitamin D content of breastmilk is even lower in dark-skinned mothers or mothers with other causes of vitamin D deficiency. ${ }^{[8]}$ A study that included black and white infants estimated that most breastfed infants need to be exposed to sunlight for at least 30 minutes/week while wearing only a nappy in order to maintain $25(\mathrm{OH}) \mathrm{D}$ levels at $>20 \mathrm{ng} / \mathrm{mL}(50 \mathrm{nmol} / \mathrm{L}) .{ }^{[9]}$ This amount of sun exposure is unlikely, given current recommendations to limit sun exposure in infants $<6$ months old.

The advantage of sun exposure in providing vitamin $\mathrm{D}$ needs to be balanced against the potential risk of skin cancer from excessive exposure to UV radiation, particularly melanoma, which is one of the most common forms of cancer among young adults - especially lightskinned individuals. These concerns have led to recommendations that direct sunlight exposure should be avoided in infants $<6$ months old, and that sun exposure should be limited in older children through the use of protective clothing and sunscreen. ${ }^{[10]}$

\section{High-risk groups}

A number of previously recognised risk factors for vitamin D deficiency and insufficiency are listed in Table 1. These factors, however, fail to emphasise the problem of insufficiency in regions with high sunlight exposure.

Based on many considerations, currently accepted standards for defining vitamin D status in children and adolescents are as follows: ${ }^{[11-13]}$

- Vitamin D sufficiency: $25(\mathrm{OH}) \mathrm{D} \geq 20 \mathrm{ng} / \mathrm{mL}$ (50 nmol/L)

- Vitamin D insufficiency: 25(OH)D between 15 and $20 \mathrm{ng} / \mathrm{mL}$ $(37.5-50 \mathrm{nmol} / \mathrm{L})$

- Vitamin D deficiency: 25(OH)D $\leq 15 \mathrm{ng} / \mathrm{mL}$ (37.5 nmol/L).

Table 1. Known risk factors for vitamin D deficiency and insufficiency in children

- Exclusively breastfed infants, particularly if the mothers were vitamin D deficient during pregnancy

- Premature infants

- Children with chronic illnesses, especially liver and kidney disease

- Malnourished children

- Dark-skinned children

- Living at higher latitudes

- Limited sun exposure

- Developed nations; if sufficient vitamin D intake is not ensured through the use of supplements and fortified foods, particularly if exposure to sunlight is limited

- Use of certain medications, e.g. anticonvulsants or antiretrovirals

- Malabsorptive conditions

- Children on glucocorticoid treatment, which inhibits intestinal vitamin D-dependent calcium absorption 


\section{Prevalence of vitamin D insufficiency in Africa and the Middle East}

Vitamin D insufficiency and deficiency are common across these regions, with studies in South Africa (SA) reporting insufficiency in $19 \%$ of 10 -year-old children and deficiency in $7 \% .{ }^{[14]}$ In Nigeria, $83 \%$ of Fulani women were reported to by deficient ${ }^{[15]}$ and in the United Arab Emirates (UAE) a study reported $50 \%$ of pregnant women being deficient. ${ }^{[16]}$ In Saudi Arabia, a study found 59\% of healthy 4 - 15-year-old schoolchildren to be deficient and $28 \%$ insufficient in vitamin $D .{ }^{[17]}$ Studies in every country in this region reveal significant numbers of individuals with vitamin D insufficiency and deficiency.

\section{Aetiological factors for vitamin D insufficiency and deficiency in Africa and the Middle East}

The following factors have been reported to be associated with vitamin D insufficiency and deficiency in Africa and the Middle East: black race and seasonality in SA children; ${ }^{[14]}$ inactivity; smoking; injectable progestin contraceptive use; high alcohol consumption and diets low in calcium and high in animal protein; phosphorus and sodium intake in SA adults; $;^{[18]}$ diets rich in corn and cassava; ${ }^{[19]}$ diets rich in unfortified dairy products in Nigerian adults; ${ }^{[15]}$ fast-food diets in the UAE; ${ }^{[20]}$ women in purdah, ${ }^{[21]}$ traditional or religious dress; ${ }^{[15,21]}$ socioeconomic status in Nigerian adults; ${ }^{[22]}$ exclusive breastfeeding in Nigerian children; ${ }^{[15,20,21]}$ indoor lifestyle in Nigeria; ${ }^{[15,20]}$ chronic disease in Egyptian adults, ${ }^{[23]}$ and adolescent girls in Iran and Saudi Arabia; ${ }^{[24,25]}$ anaemia in a group of adults living in Riyadh, Saudi Arabia; ${ }^{[26]}$ lack of sunlight exposure ${ }^{[16]}$ and body mass index in the UAE. ${ }^{[27]}$

\section{Conclusion}

Should the new diseases related to hypovitaminosis D prove to be truly associated, then Africa and the Middle East will become an epicentre for many of these conditions. Urgent attention will need to be paid to cultural dress and dietary behaviours if hypovitaminosis $\mathrm{D}$ is to be taken seriously. Should such factors not be correctable, new strategies for supplementation or food fortification will urgently need to be devised.
References

1. Misra M, Pacaud D, Petryk A, Collett-Solberg PF, Kappy M. Vitamin D deficiency in children and its management: Review of current knowledge and recommendations. Pediatrics 2008;122(2):398-417. [http://dx.doi.org/10.1542/peds.2007-1894]

2. Hollis BW. Circulating 25 -hydroxyvitamin D levels indicative of vitamin D sufficiency: Implications for establishing a new effective dietary intake recommendation for vitamin D. J Nutr 2005;135:317-322. 3. Holick MF. Photosynthesis of vitamin D in the skin: Effect of environmental and life-style variables. Fed Proc 1987;46:1876-1882.

Matsuoka LY, Ide L, Wortsman J, MacLaughlin JA, Holick MF. Sunscreens suppress cutaneous vitamin D3 synthesis. J Clin Endocrinol Metab 1987;64:1165-1168.

5. Tangpricha V, Turner A, Spina C, Decastro S, Chen TC, Holick MF. Tanning is associated with optimal vitamin D status (serum 25-hydroxyvitamin D concentration) and higher bone mineral density. Am J Clin Nutr 2004;80:1645-1649

6. Del Arco C, Riancho JA, Luzuriaga C, González-Macías J, Flórez J. Vitamin D status in children with Down's syndrome. J Intellect Disabil Res 1992;36:251-257.

7. Greer FR. Fat-soluble vitamin supplements for enterally fed preterm infants. Neonatal Netw 2001:20:7-11.

8. Specker BL, Tsang RC, Hollis BW. Effect of race and diet on human-milk vitamin D and 25-hydroxyvitamin D. Am J Dis Child 1985;139:1134-1137.

9. Specker BL, Valanis B, Hertzberg V, Edwards N, Tsang RC. Sunshine exposure and serum 25-hydroxyvitamin D concentrations in exclusively breast-fed infants. J Pediatr 1985;107:372-376.

10. Committee on Environmental Health. Ultraviolet light: A hazard to children. Pediatrics 1999;104:328333.

11. Misra M, Pacaud D, Petryk A, et al. Vitamin D deficiency in children and its management: Review of current knowledge and recommendations. Pediatrics 2008;122:398-417. [http://dx.doi.org/10.1542/ peds.2007-1894]

12. Boonen S, Rizzoli R, Meunier PJ. The need for clinical guidance in the use of calcium and vitamin D in the management of osteoporosis: A consensus report. Osteoporos Int 2004;15:511-519.

3. Lips P. Vitamin D deficiency and secondary hyperparathyroidism in the elderly: Consequences for bone loss and fractures and therapeutic implications. Endocr Rev 2001;22:477-501.

14. Poopedi MA, Norris SA, Pettifor JM. Factors influencing the vitamin D status of 10-year-old Poopedi MA, Norris SA, Pettifor JM. Factors influencing the vitamin D status of 10-year-old
urban South African children. Public Health Nutr 2011;14(2):334-339. [http://dx.doi.org/10.1017/ urban South African
S136898001000234X]

15. Glew RH, Crossey MJ, Polanams J, Okolie HI, VanderJagt DJ. Vitamin D status of seminomadic Fulani Glew RH, Crossey MJ, Polanams J, Okolie HI, Vanderjagt
men and women. J Natl Med Assoc 2010;102(6):485-490.

16. Dawodu A, Dawson KP, Amirlak I, et al. Diet, clothing, sunshine exposure and micronutrient status of Arab infants and young children. Ann Trop Paediatr 2001;44:39-44.

17. Arab infants and young children. Ann Trop Paediatr 2001;44:39-44.
Mansour Alhadidi KM. Vitamin D deficiency in children living in Jeddah, Saudi Arabia. Indian J Mansour MM, Alhadidi KM. Vitamin D deficiency in children living in Jeddah, Sau
Endocrinol Metabol 2012;16:263-269. [http://dx.doi.org/10.4103/2230-8210.93746]

18. Kruger MC, Kruger IM, Wentzel-Viljoen E, Kruger A. Urbanization of black South African women Kruger MC, Kruger IM, Wentzel-Viljoen E, Kruger A. Urbanization of black South African women
may increase risk of low bone mass due to low vitamin D status, low calcium intake, and high bone may increase risk of low bone mass due to low vitamin D status, low calcium intake, and
turnover. Nutr Res 2011;31(10):748-758. [http://dx.doi.org/10.1016/j.nutres.2011.09.012]

turnover. Nutr Res 2011;31(10):748-758. [http://dx.doi.org/10.1016/j.nutres.2011.09.012]
19. Maziya-Dixon BIO, Akinyele EB, Oguntona S, et al. Nigeria Food Consumption and Nutrition Survey Maziya-Dixon BIO, Akinyele EB, Oguntona S, et al. Nigeria Food Consumption and Nutrition Survey 2001 - 2003. Summary. Ibadan, Nigeria: International Institute or Tropical Agriculture (IITA), 2005. 20. Okonofua F, Houlder S, Bell J, Dandona P. Vitamin D nutrition in pregnant Nigerian women at term
and their newborn infants. J Clin Pathol 1986:39(6):650-653. and their newborn infants. J Clin Pathol 1986,39(6).650-653.

1. Sanchez PA, Idrisa A, Bobzom DN, et al. Calcium and vitamin D status of pregnant teenagers in Maiduguri, Nigeria. J Natl Med Assoc 1987;89(12):805-811.

22. Ene-Obong HN, Enugu GI, Uwaegbute AC. Determinants of health and nutritional status of rural Nigerian women. J Health Popul Nutr 2001;19(4):320-330.

23. Gannagé-Yared MH, Chedid R, Khalife S, Azzi E, Zoghbi F, Halaby G. Vitamin D in relation to metabolic risk factors, insulin sensitivity and adiponectin in a young Middle-Eastern population. Eur $\mathrm{I}$ Endocrinol 2009;160:965-971. [http://dx.doi.org/ 10.1530/EJE-08-0952]

24. Moussavi M, Heidarpour R, Aminorroaya A, et al. Prevalence of vitamin D deficiency in Isfahani High School students in 2004. Horm Res 2005;64:144-148

25. Siddiqui AM, Kamfar HZ. Prevalence of vitamin D deficiency rickets in adolescent school girls in Western region, Saudi Arabia. Saudi Med J 2007;28:441-444.

26. Abdulkareem O, Alsuwaida YM, Farag, et al. Prevalence of vitamin D deficiency in Saudi adults. Saudi Med J 2013;34(8):814-818.

27. Muhairi SJ, Mehairi AE, Khouri AA, et al. Vitamin D deficiency among healthy adolescents in $\mathrm{Al}$ Ain, United Arab Emirates. BMC Public Health 2013;13:33. [http://dx.doi.org/10.1186/1471-2458-13-33] 